about the elderly that he believes serve to maintain the structure of policies and practices favouring the 'better off' majority, argues for greater realism in public policy making, warns against too great reliance on the family unit as a crucial support structure, and is critical of the incrementally developed, patchwork system of benefits. The fact that such funded programmes absorb one-third of the federal budget and additional billions of tax subsidy and non-public dollars is a burden, warns Crystal, that future generations of younger working-age populations may find themselves unable or unwilling to bear. Crystal's prescription for lessening the gap between the 'better off' and 'worse off' groups of elderly persons appears eminently rational, and modest when viewed against the canvas of the 'crisis' he portrays.

Students and close observers of the aged in the U.S. may find in this volume little that is startling or new, or that has not, at least in part, been said elsewhere. Certainly Crystal's recommended policy changes or alternatives will hardly appear novel or even sufficiently far-reaching or deep enough to some. But the main contribution of this work lies, at least to this reviewer, in its comprehensive coverage of the issues, its balanced blend and wide scope of perspective and data sources, and its insistence on coherence and clarity in designing policy and policy objectives, bearing in mind not only short-term outcomes but long-range goals as well.

HOWARDR. KELMAN

Srate University of New York, Stony Brook, New York

Emily M. Nett (ed.), Women as Elders, Resources for Feminist Research, Vol. I I, No. 2, July 1982, 77 pp., ISSN 0707-84 I 2.

Any publication about women and ageing is welcome because the visibility of women in this area-even by comparison with the increasingly acknowledged invisibility of women in areas such as education, arts, medicine, the marketplace and everywhere else - seems to be near zero. Studies of ageing in sociology or gerontology may note sex differences, but rarely differentials. Even more rarely do they take into account the structural inequality of women in relation to men from birth to death and what this might mean when looking at the 'problems' of the 'the aged' or 'the elderly'.

The general assumption is that ageing is a biological/psychological/sociological process which affects men and women much the same. So the conditions of women in the process of ageing have been almost wholly subsumed within those of men (when they have been addressed at all). These sex-blind assumptions persist despite the increased awareness of the universal subordination of women revealed by the work of the Women's Movement and by feminist research. Indeed, as this issue of Resources for Feminist Research (a Canadian journal for feminist scholarship) devoted to the subject of women as elders, confirms, feminist research has overlooked the issue of women and ageing as much as research on ageing has obscured the issues of women.

The discussion articles that fill the first half of this volume are excellent in 
making the silenced majority more visible. Thus the address published here by Dr Linda Rhodes to the United Nations Committee on Aging last year ( 1982 ) leaves no doubt as to the world-wide statistics concerning women's existence as elders.

The figures are straightforward: of those over sixty years, women are the significant majority (over half) everywhere in the world; life expectancy for women is substantially higher than for men... yet women rarely surface as the central issue in aging.

Nor does she leave any doubts as to the sites and causes of the oppression:

In most cultures, women are valued primarily for childbearing and kinkeeping roles. This position in society is often considered secondary to the male role of provider. The rewards for women in these roles are rarely economic... once there are no children to bear or kin to keep, women are without a position.

Of course, this must affect the meaning of retirement for women (if its present conceptualisation has any meaning at all). Or the meaning of money (security, pensions, poverty) for women. Or the meaning of marriage and motherhood and widowhood. Or, in the case of my own research, the meaning of sexuality. Of course, in this context, being old has a different meaning, is a different experience for women than men.

Other articles look at sex differences in ageing in the experimental literature in psychology, the lives of middle-aged women, at women as carers, the use of interactionist rather than normative models in gerontological research, at women in rural societies: and much more. And there is a call from the volume's editor for feminist correctives to research on elders.

There is a useful section of book reviews, the syllabi used at three Canadian and one U.S.A. university in the study of 'the sociology of aging' which redress the sexist balance and include reading lists (excellent models for other such courses), and an immensely useful annotated bibliography on women as elders.

In my view this publication points the way forward for research on ageing - putting the focus on women as women, and by implication, but equally as important, on men as men. Acknowledging the ways in which living is different and difficult for women as distinct from men, as well as the ways in which life is difficult for women and men because of their age. In short, taking into account sexism as well as ageism.

\section{University of Kent, Canterbury}

CATHERINE ITZIN

S. M. Peace, L. A. Kellaher and D. M. Willcocks, A Balanced Life?, Survey Research Unit, The Polytechnic of North London, I982, 52 pp., ISBN o 90697 or $3 \mathrm{X}$.

L. Hanaway, (ed.), The Three-in-one House, Home Care Research Inc., Frederick, Maryland, $198 \mathrm{I}, 46 \mathrm{pp}$.

Researchers are for ever being criticised for their failure to communicate research findings to practitioners. Both of these books, in their different ways, are intended to change practices with regard to the elderly. A Balanced Life? 